\title{
169 KELVIN CRYOGENIC MICROCOOLER EMPLOYING A CONDENSER, EVAPORATOR, FLOW RESTRICTION AND COUNTERFLOW HEAT EXCHANGERS
}

\author{
Johannes Bu rger, Harry Holland, Er win Berenschot, Jan-Henry Seppenwodde, \\ Marcel ter Brake, Han Ga rdeniers and Miko Elwenspoek \\ MESA ${ }^{+}$Research Institute, University of Twente, P.O. Box 217, 7500 AE Ensch ede, The Netherlands
}

\section{ABSTRAC T}

This paper presents the first cryogenic micromachined cooler that is suitable to cool from ambient temperatureto 169 kelvin and below. The cooler operates with the vapor compression cycle. It consists of a silicon micromachined condenser, a flow restriction/eraporato and two miniature glass-tube counterflow heat exchangers, which are integratedwith the silicon components using a novel gluing technique. The system was tested with ethylene gas from 20 to 1 bar, and produces a cooling power, of $200 \mathrm{~mW}$ at $169 \mathrm{~K}$ with a mass flow of $0.5 \mathrm{mg} / \mathrm{s}$.

\section{INTROD UCTION}

During recent years, there has been much interest to remove locally produced heat from chips, essentially around normal ambient temperatures [1]. Minia ture applications operating below ambient temperature, such as a single low-noise amplifier chip or a superconductig chip, would benefit from very small cryocoolers [2]. Such coolers are not available. At the University of Twente, a closedcycle microcooler is developed which consists of the microcooler presented in this paper connected to a sorption compressor. This precision engineeredstainless steel compressor is able to produce the required gas pressures without the use of moving components, except for some high pressure check valves. These MEMS-based valves were presented at MEMS ' 99 [3]. A thermodynamic descriptionand analysis of the complete cooler was presented earlier [4].

\section{THEORY}

Figure 1 shows a schematic diagram of the cooler; it operates with the vapor compression cycle [5]. The accompanying thermodynamic cycle in a temperature-entropy diagram is given in

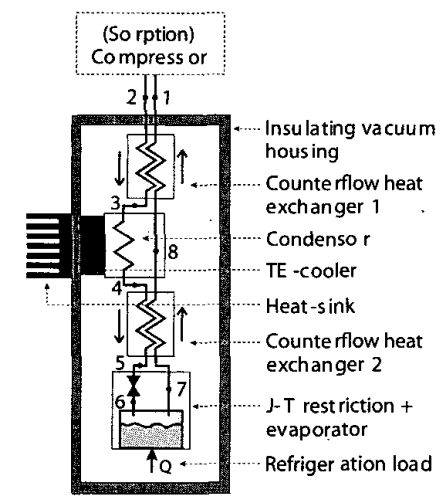

Figure 1. Schematic cooler diagram

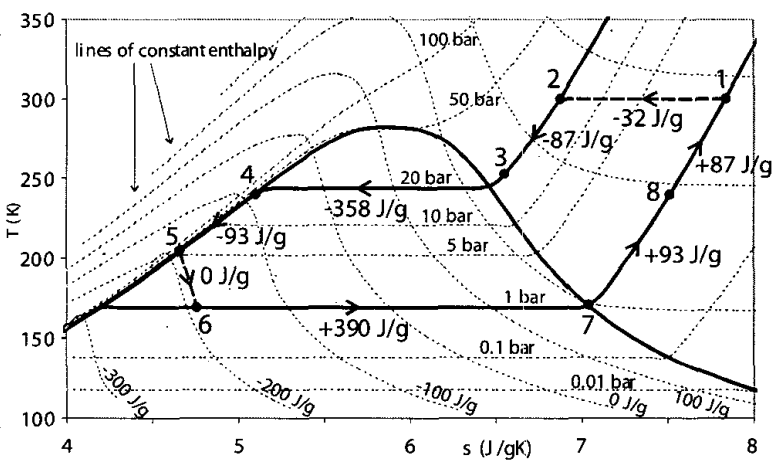

Figure 2. Thermodynamic cycle of the ethylene cooler in a T-s diagram.

figure 2. In the diagram isobars and isenthalpsare given, as well as the enthalpy changes that occur in the counterflow heat exchangers, condenser and evaporator, assuming ideal operation. After compression (1-2), the high pressure gas is precooled (2-3) by the returning low pressure gas (8-1) in the first counterfow heat exchanger. In the condenser, the high pressure vapor is condensed (3-4) using a miniature thermolectric cooler (which cannot be used to cool directly to temperaturesbelow about $210 \mathrm{~K}$ due to a dramatic reduction in performance). The condenseris not essential for operation of the cycle, but it increases the available cooling power per unit mass flow with a factor of ten. Further cooling (4-5) occurs in the second counterflow heat exchanger by the returning low pressure vapor (7-8). The low temperature is reached by a pressure reduction through Joule-Thombon expansion (5-6). Evaporation of the low pressureliquid in the boiler (6-7) produces the cooling power, which can be used by some thermal load connectedto the silicon evaporabr.

When the cycle operates ideally, the cooling power is given by in $h_{67}$, where $h$ is the mass flow and $h_{67}$ the enthalpy change between states 6 an 7 . To obtain agross cooling power of $200 \mathrm{~mW}$, for instance, an ethylene mass flow of $0.5 \mathrm{mg} / \mathrm{s}$ is needed. The majority of the enthalpychange $h_{67}$ is created during condensation from state 3 to 4 . A proper design of the condenseris, therefre, a major requirement so that the two-phase fluid reaches full condensation atstate 4 .

To obtan a significant net cooling power, the thermal losses on the cold stage (conduction and raliation) should be small relative to the gross cooling power. Al so the conduction from the warm to the cold side of the counterflow heat exchangers should be limited. Because silicon has a very high thermal conductivity a different material with a low conductivity such as glass should be used for the construction of the counterflow heat exchangers. In contrast, it is attractive to use a high conductivity material (silicon) for the condenser and evaporator to maintain uniform temperatures, independentof the suppliedthermal loads. 


\section{DESIGN}

Figure 3 shows the design of the cooler. It is made of three micromachined silicon components, each with a size of $9 \mathrm{~mm} \times 9 \mathrm{~mm}$ with two glass-tubecounterfow heat exchangers in between All three silicon parts are constructedby fusion bonding of two $500 \mu \mathrm{m}$ thick silicon wafers in which channels and spaces are etched by $\mathrm{KOH}$ etching. The applied glass tubes are commercially available [6] and have innerbuter diameters of $0.25 / 0.36 \mathrm{~mm}$ and $0.53 / 0.67 \mathrm{~mm}$, respectively. Two glass suppot tubesare addedparallel to the two counterfow heat exchangers to add more stability to the system.

The top silicon part is called the 'splitter', andmakes it possible to supply separate connectionlines to the high and low pressure channels of the first counterfow heat exchanger. In the condenser, the high pressurefluid is able to condensein the long meandering channel. The low pressure fluid retuming from the second counterfow heat exchanger directly connects in the condenserto the low pressure annulus of the first counterfow heat exchanger. The high pressure fluid that enters the restriction/evaporatorflows throughan etched channel to the entrance of the flow restriction, which typically consists of a $4 \mathrm{~mm}$ wide, $1 \mu \mathrm{m}$ shallow channel with a length of about $3 \mathrm{~mm}$ The low pressureliquid that exits the
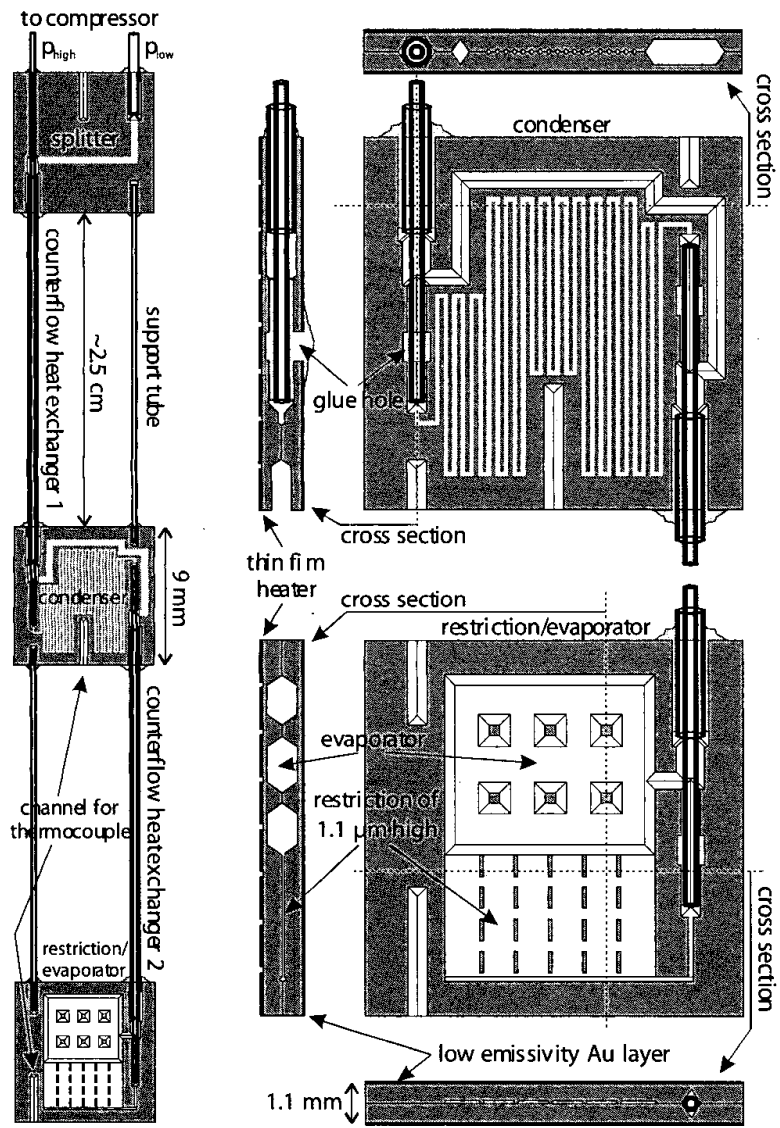

Figure 3. Cooler design (l eft) with enlargemert of the condenser and restriction/evapoator structure (right). flow restriction (in state 6 in figures 1 and 2) is collected in the liquid bath of the evaporator, which connects at the top side to the low pressureannulus of the second counterflowheatexchanger. In the presentdesign, the orientation of the cooler is important: the low pressure exit of the liquid bath should be oriented vertically upward so that gravity keeps the liquid in the bath and only vapor exits the liquid bath, except when the liquid bath is full. Both the flow restriction and the boiler structure are supportedby pillars to prevent excessive bendingstresses due to the high gas pressure of 20 bar that may be present. Furthermore, the condenserand the restriction/evaporator contain etched channels that can be used to insert external $250 \mu \mathrm{m}$ thick thermocouples to measure the temperatures ofthese cooler parts

The high pressure inner glass tubes areglued intothe condenser and restriction/evaporatovia a so-called 'glue hole', whereas the outer glass tubeis glued at the entrance of the sample, see figure 3. This construction facilitates a robust separate connection of the high and low pressures.

The surface area of the condenserfits approximately to the surface of a two stage themoelectric cooler, which is a MI 2012Ttype fabricated by Marlow Industries [7]. In the same way, a thermal load (some device) can be attached to the restriction/eaporato. In the current design however, for test purposes a thin film heater is deposite on the restriction/evaporatorad on the condenser. This heater can be usd to study the behavior of the cooler. To limit the radiation load on the cooler, a gold layer is deposited onboth sides ofthe cooler.

Fluidic, thermal and mechanical modelling was applied to find the proper dimensions of the condenser, evaporator and counterfow heat exchangers[5].

\section{FABRICATION}

Figure 4 shows the essential processing steps for the cooler fabrication. Both wafers are double side polishedwafers.

Wafer 1. (1) $1.0 \mu \mathrm{m}$ LPCVD silicon nitride is grown on both sides and patternedby RIE as a mask for $\mathrm{KOH}$ etching of the deep channels and the glue holes. Next, the mask for the flow restriction is preparedby etching (RIE) the nitride to $0.5 \mu \mathrm{m}$ thickness. (2) The deepchannelsare made by $\mathrm{KOH}$ etching; for narrow channds the dept is fixed by the width of the V-shaped channel and for wide channels the deph is fixed by the etching time. (3) The mask for the flow restriction that was etchedin step 1 is now activated by

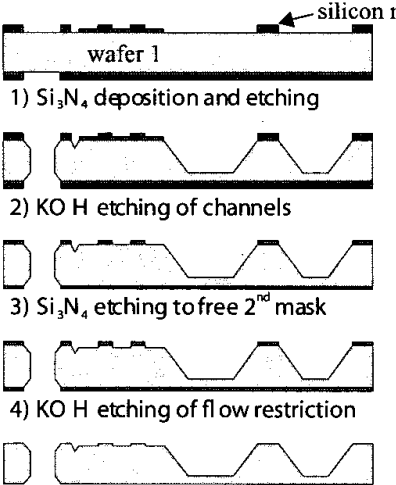

5) $\mathrm{Si}_{3} \mathrm{~N}_{4}$ etching

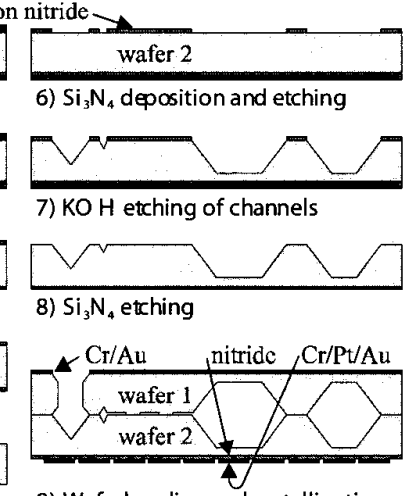

9) Wa ferbonding and metalliz ation
Figure 4. Processing steps for the cold stage fabrication. 


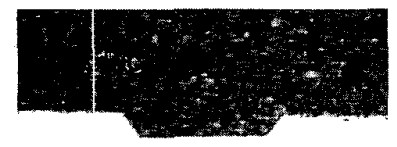

silicon

(a)

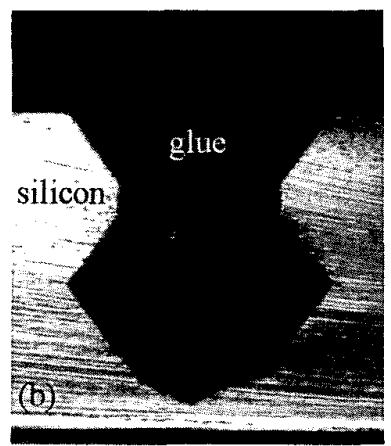

Figure 5. Cross section of a leaking glue-comection (a) and a properglue-connection (b).

removing $0.5 \mu \mathrm{m}$ nitride by means of $50 \% \mathrm{HF}$ etching. (4) Next, the $1.1 \mu \mathrm{m}$ deep flow restriction is etched by a very short $\mathrm{KOH}$ etching step. (5) Just prior to the bonding step, the nitride mask is removed using $50 \% \mathrm{HF}$ etching.

Wafer 2. (6) $1.0 \mu \mathrm{m} \mathrm{LPCV} \mathrm{D} \mathrm{nitride} \mathrm{is} \mathrm{grown} \mathrm{on} \mathrm{both} \mathrm{sides} \mathrm{of}$ the wafer and subsequetly etched back to $0.5 \mu \mathrm{m}$ at the topside of the wafer by meansof RIE. Next, the mask for $\mathrm{KOH}$ etching of the deepchannels is patternedon the topsideof the wafer by RIE. (7) The channels are etchedby a KOH etching step similar to step 2 . (8) Just prior to the bonding step, the $0.5 \mu \mathrm{m}$ thick nitride mask is removed from the topside of the wafer using $50 \% \mathrm{HF}$ etching, leaving $0.5 \mu \mathrm{m}$ nitride on the backside of the wafer. This nitride layer will serve as an electrical isolation layer for the heater, which is deposted on top of the nitride in a later step.

Bonding and sample preparation. (9) Wafers 1 and 2 are connectedusing aligned direct wafer bondng techniques. The two wafers are annealedat $1100^{\circ} \mathrm{C}$ in nitrogen atmosphere to enhane the bondstrength.Af ter this annealingstep, a $\mathrm{Cr} / \mathrm{Au}$ metal layer is sputteredon top of the two wafers to reduce the emissivity of the top surface; the $10 \mathrm{~nm}$ thick $\mathrm{Cr}$ layer serves as an adhesionlayer. Next, a heater is made on the backside of the wafers by mears of dry lift-off patterning A stack of $\mathrm{Cr} / \mathrm{Pt} / \mathrm{Au}$ is used: $10 \mathrm{~nm} \mathrm{Cr}$ is the adhesionlayer, $400 \mathrm{~nm} \mathrm{Pt}$ is the actual heater-resistancelayer and the $50 \mathrm{~nm}$ Au layer reduces the emissivi ty of the backside surface. Finally, the wafers are sawed into strips of samples. Single samples are obtrined by breaking the strips, thus freeing the heat exchanger entrance holes without contaminating theholes by sawing them

Cold stage integration. Prior to gluing of the cold stage, the heater connection wires are soldered to the heater. Next, the capillany glass tubes for the heat exchangers and supports are

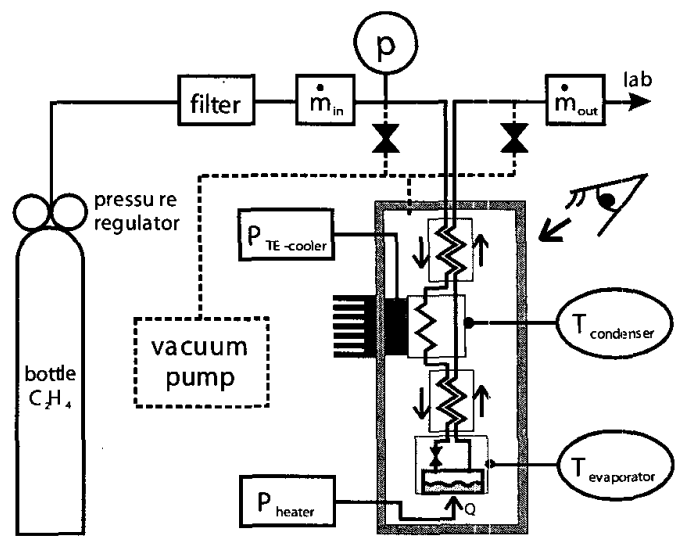

Fi gure 7. Schematicpicture of the cooler characterization set-up.

accurately cut to the required length after which integration and gluing follows.

Ex perimentswere doneto test the resistarice of different epoxy glues to thermal cycling of the system Va rian's Torr Seal [8] was found to be suitable in this respect. Al so, experiments were doneto find a proper size for the glue hole. Figure $5 \mathrm{a}$ illustrates the result for a small glue hole: the glue could not reach all corners around the glass tube, resulting in a leaking connection of the tube Widening of the glue hole resulted in properly sealed tubes, see figure $5 b$.

\section{EXPERIMENTS}

Differ ent versions of the cooler were characterized in the set-up shown in figure 7. The high pressure input of a cooler was connectedto an ethylene gas bottle, with a zeolite filter in between to trap possible contaminant gases. A data-acquisitionsystem was used to messure and store the following parameters: the temperatures of the condenser and evaporator, elinput povers into the TE -cooler and heater, the input high pressureand the mass flow going into the system and coming out of the system A typical measurement is depicted in figure 8 ; the important steps are numbered inthe figure and are dicussed below

(1) The high pressure is supplied to the cooler and the evaporator cools to a temperature slightly below ambient. The cooling power correspondingto the enthapy change producedat ambient temperature, $h_{12}$ is too small to overcome the thermal losses and reach lower temperatures. (2) The TE -cooler is started
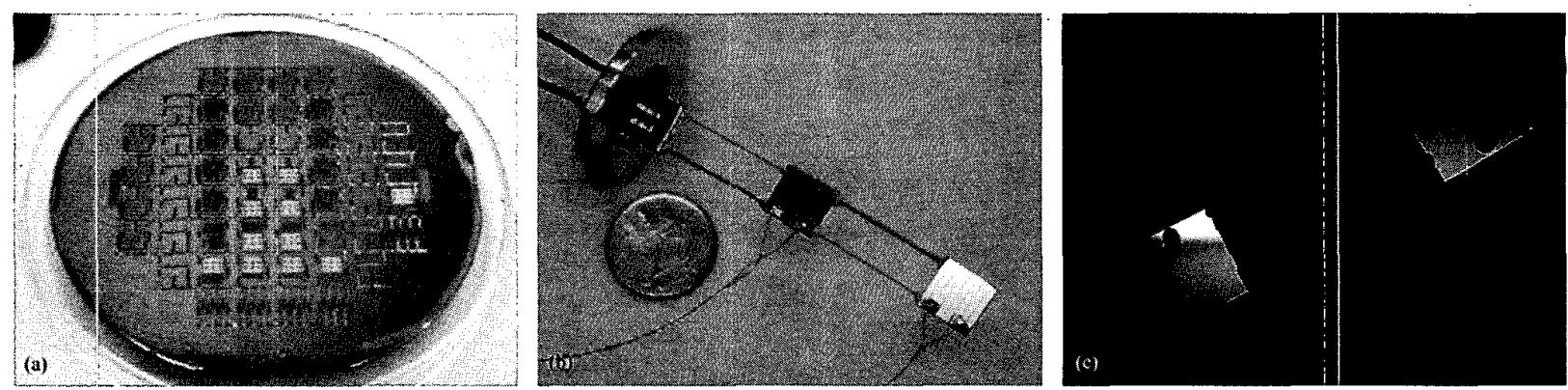

Figure 6. (a) Structured 4" silic on wafer after the first KOH etching step.(b) Assembled cold stage connectedb a vacuum flange. The wires are soldered on thethin film heater. (c) Opposite side of thecondenser and evapordor with excess glueon the glue holes. 
and temperature-controllectat $238 \mathrm{~K}, 6 \mathrm{~K}$ below the condensation temperature at 20 bar. As long as the condenser temperature is above $238 \mathrm{~K}$, a maximum input power of $4.5 \mathrm{~W}$ is put in the TE cooler. (3) The fluid starts tocondensein thecondenser. For a short period the ingoing mass flow exceeds the outgoing mass flow to compensate for the liquid volume that is now being collected in the condenser.Al so, the evaporatorstarts to cool more rapidly because of the increased cooling power of the liquid ethylene that now flows from the condenser to the evaporator. As long as the temperature of theevaporator is above the saturation teperature of ethylene at 20 bar $(244 \mathrm{~K})$, the producedliquid will evaporateupon reaching the silic on evaporatorsample - thus providing cooling power to cool the sample. (4) The high pressurefluid now starts to enter the restriction as a liquid, which increases the mass flow because of changing fluid density and viscosity. This increase of mass flow requires more cooling power to condensethe fluid in the condenser and, therefore, the input power of the TE-cooler increases. (5) The low pressureboiling temperatureis reachedand the boiler starts to fill with low pressureliquid. This explains why the ingoing mass flow exceed the outgoing mass flow for a while. The outflow does not reach zero because of a partial evaporation of the produced liquid, caused by the heat load from the environment and cooling of the incoming high pressure liquid. Integration over time of the difference between the inflow and the outflow closely matchesthe amount of liquid tha can be storedin the boiler, which is about7 mg (6) Because the cooling power exceeds the applied thermal load, two-phasefluid exits the evaporator.Capillary effects explain the variations in the outgoing mass flow. The excess low pressureliquid that flows from the evaporatorto the condenserwilt first exchange heat with the high pressure liquid in the second counterfow heat exchanger, and then evaporateupan entrance of the condenser. This gives cooling power, which is subtractedfrom the TE -cooler. This explains the slight reduction of the input power of the TE -cooler after $t=420 \mathrm{~s}$.

In the measurementof figure 9 , the thin-film heater on the evaporatoris used to determine the net cooling power. At an input power of $155 \mathrm{~mW}$, the liquid in the boiler starts to evaporatewhich indicates that the total thermal load (heater + losses) exceeds the gross cooling power. The losses of approximately $55 \mathrm{~mW}$ are mainly caused by radiation on the evaporator and conduction through the $200 \mu \mathrm{m}$ thick coppe wires to the heater. The first two rapid temperature increases are caused by capillary forces, which play an important role because ofthe small channel dimensions.

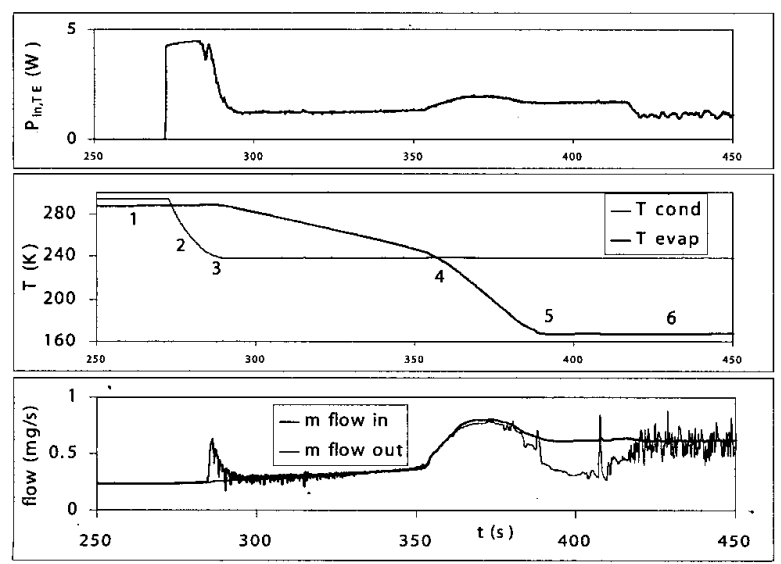

Figure 8. Typical measurementof a start-up of the cold stage.
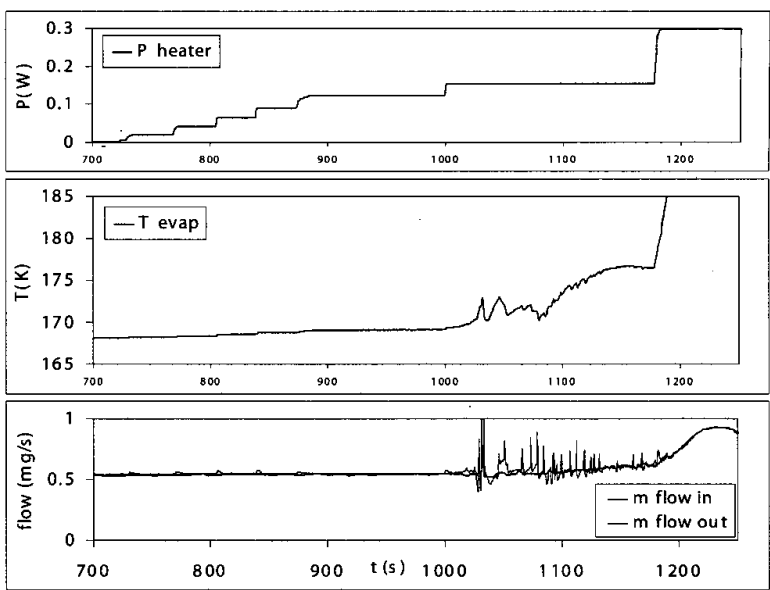

Figure 9. Stepby-step increase of the heater load on the evaporator. At $\mathrm{P}_{\text {heater }}=155 \mathrm{~mW}$, the boiler contents evaporates.

\section{CONCLUSIONS AND OUTLOOK}

In condusion we have shown that MEMS technologies can succesfully be applied to construct components for use in cryocoolers. Counterfow heat exchangersmade of glass tubes wee succesfully fabricated and integrated with silicon components using a novel gluing technique resulting in a working $169 \mathrm{~K}$ microcooler. Other temperatures can be reached by replacing ethylene with a different refrigerant. Future oppotunities exist in the development of an integratedME MS micro-cryocooler with vacuumhousing.

\section{ACKNOWLEDGMENTS}

This research was supported by the Dutch Technology Foundation (STW). The authors would like to acknowedge the valuable contrbutions of David Agar, who did much work on the initial fabrication of the codd stage components.

\section{REFERENCES}

[1] D.B. Tuckerman et al., "High peformance heat sinking for VL SI", IEEE El ectron Dev Let, ED L- 2 (1981).

[2] G. Walker and R. Bi ngham " $M$ icro and nano cryocoders: speculation on future development", Proc of the $6^{\text {th }}$ Int. Cryocoder Conf. (1990), pp 363-375.

[3] J.F. Burger, M.C. van de Wekken, E. Berenschot, H.J. Holland, H.J.M. te Brake, H. Rogala, J.G.E. Gardeniers and M. El wenspœk, "High pressure check valve for application in a miniature cryogenic sorption cooler", Proc. of the $12^{\text {th }} I E$ EE MEMS Conf. (1999).

[4] J.F. Burger, H.J. Holland, H.J.M. ter Brake, H. Rogalla, "Thermodynamic considerations on a microminiature sorption cooler", Cryocoolers 10 (1998), pp. 553-564.

[5] J.F. Burger, Cryogenic microcooling A micromachined cold stage operating with a sorption compressor in a vapor compression cycle, Ph.D. Thesis, Twente University, The Netherlands (2001).

[6] Supelco/Sigma-Al drich Corp., Bellefonte PA, USA

[7] Marlow Ind., 10451 Vi sta Park Road, Dallas, Texas 75238-1645, USA .

[8] Varian Vacuum Techndogies, 121 Hartwell Avenue Lexington, MA 02421, USA 